\title{
Analysis on the Economic Space Dynamic Mechanism and Innovation Model for the Development of Creative Industrial Districts
}

\author{
Jiayu Wang \\ School of Journalism and Communication \\ Xi'an International Studies University \\ Xi'an, China
}

\author{
Xu Zhang* \\ Department of Chinese Culture \\ The Hong Kong Polytechnic University \\ Hong Kong, China \\ *Corresponding Author
}

\begin{abstract}
Influenced by the economic globalization trend, the enterprises are faced with ever-increasingly fierce competition and the industrial district are also confronted with great competition in the development course. The economic space dynamic mechanism and innovation model for the development of industrial districts has an important influence on their long-term advancement. At the same time, in the development process of the creative industrial districts, the embodiment of "creativity" is more focus on the market conditions. To exert the economic space dynamic mechanism, it requires concentrating efforts on the innovation development.
\end{abstract}

Keywords-creative industrial districts; economic space dynamic mechanism; innovation model

\section{INTRODUCTION}

Cultural and creative parks are the products when the tourism industry develops to a certain stage, and closely relevant to the tourism industry. At the same time, cultural and creative parks are, based on the development of the creative industry, developing new tourism resources under the traditional development model of the tourism industry, and better realize economic benefits. In the process, the analysis on the economic space dynamic mechanism and innovation model has a significance influence on promoting the realization of the economic benefits of cultural and creative parks. In the analysis process of economic space dynamic mechanism and innovation model for the development of cultural and creative parks, the paper takes "cultural and creative parks" as the investigation theme, and analyzes the economic value embodied in the development process of the cultural and creative industry.

\section{INFLUENCES FROM CULTURAL AND CREATIVE PARKS} ON THE DEVELOPMENT PROCESS OF THE TOURISM INDUSTRY

From the perspective of the development of the tourism industry, cultural and creative parks are a kind of human tourism resource based on the tourism market and created through setting cultural and creative parks. The development process of cultural and creative parks enriches the tourism form and is novel, and the creativity also creates favorable conditions for the realization of economic benefits [1]. From the perspective of the development of the tourism industry, cultural and creative parks have the following characteristics:

- Remedy the issue of insufficient tourism resources. The construction of cultural and creative parks enriches the tourism resources, by combining people's needs, the functions and roles of cultural and creative parks are well embodied. The development of cultural and creative parks can drive the tourism consumption and improve the economic benefits of the tourism industry.

- The setting of cultural and creative parks has strong expansibility and potential. Cultural and creative parks master the development characteristics of the tourism industry, pay attention to developing the internal demand of the tourism industry, integrate the cultural factors, satisfy people's internal spiritual demands with cultural space, and provides important fundamentals and guarantees for cultural and creative parks in gaining profits.

- In the development process of the current tourism industry, influenced by the environmental carrying capacity, its functions are gradually weakening. Meanwhile, as tourists don't have sufficient awareness of environmental protection, the tourist areas are damaged. Under such environment background, cultural and creative parks, from the perspective of the tourism industry, start from the economic space dynamic mechanism, bring some supports for the development of the tourism industry, and realizes the innovative development of the tourism industry.

\section{ANALYSIS ON THE ECONOMIC SPACE DYNAMIC MECHANISM AND INNOVATION MODEL FOR THE DEVELOPMENT OF CREATIVE INDUSTRIAL DISTRICTS}

In the research process of the development issue of creative industrial areas, the paper considers the new-type tourism development model of "cultural and creative parks" 
as the research objective. In the process, the development of creative industrial districts attaches great importance to the perspective of innovation on the basis of the original industry, and the economic benefits can be better realized in a creative development pattern.

\section{A. Analysis on the Economic Space Dynamic Mechanism}

Cultural and creative parks are an outstanding expressive form of the development of creative industrial districts, they are not natural tourism resources, but are equipped with the properties of tourism resources through artificial reform. In the analysis process of economic space dynamic mechanism, from the perspective of the tourism market, cultural and creative parks are equipped with cultural elements and sightseeing property, and can generate a sense of satisfaction to people [3]. From the perspective, we can see that cultural and creative parks are equipped with the endogenous and progressive dynamic mechanism, consider culture and arts as the driving force and the market mechanism as the transmission medium, and attract the attention from enormous tourists. In the process, cultural and creative parks attach importance to the mastery of the industrial space layout and can stimulate tourists' tourism motivations.

Secondly, cultural and creative parks are a sudden and embedded economic space dynamic mechanism. In the process, the intervention from external force and consideration about the development situation of the tourism industry embody the tourism benefits of cultural and creative parks. The sudden and embedded economic space dynamic mechanism embodied by cultural and creative parks to a great degree is dominated by external driving forces, such as government supports, preferential policy support, etc.

Lastly, the synergistic but restricting dynamic model is also embodied to some extent in the development of cultural and creative parks. The synergistic but restricting dynamic model attaches importance to the many-sided supports for the development of the industry and promotes its development and advancement influenced by the joint effects. The development of cultural and creative parks is fundamentally driven by the economic benefits, in consideration of the benefits; the social subject is willing to access another industry in an innovative model and provides some guarantees for its profits. Cultural and creative parks, as a kind of creative industry, need supports from more forces; the exertion of synergistic effects can better promote their development and growth.

\section{B. Analysis on Innovation Model}

Cultural and creative parks, as a kind of creative industry, develop earlier, but still have large potentials and economic profits. The application of innovation model of cultural and creative parks attaches importance to the mastery of tourists' demands and consumption psychology, and brings great benefits for the development on the basis of satisfying tourists' demands. Generally speaking, the application of innovation model of cultural and creative parks is mainly involved with the development models of museum zones, the development models of park complexes, the cultural community models, and the development models of arts appreciation [4]. The four innovation models, through resource integration and utilization, attract a huge amount of tourists, and help the realization of economic benefits.

Regarding the application of the innovation models, it is necessary to consider about the economic development situations, combine the internal demands of the industry, innovate the original development model, and ensure better realization of the economic benefits of the innovation industry.

\section{CONCLUSION}

The aforesaid analysis process studies the economic space dynamic mechanism and innovation model for the development of the creative industrial districts, takes the development models of cultural and creative parks as the cases, and analyzes the realization methods of economic benefits. In this sense, the paper reaches the following conclusions:

Firstly, the economic space dynamic mechanism for the development of the creative industrial districts shows the development characteristic of diversification which can bring huge economic benefits to enterprises. In the analysis process of the issue of economic space dynamic mechanism, it is necessary to master the concrete characteristics of the creative industry, consider about the economic growth, ensure the application of the relevant industries, and better realize economic benefits.

Secondly, in the development process of creative industrial districts, it is necessary to effectively focus on the issue of space utilization model and innovation model; in the process, it is necessary to exert the characteristics of the creative industry, namely, high added value, high-tech content, etc., and also the revolution of the original models, better attract consumers' attention in the development process and create favorable conditions for the realization of economic benefits.

Lastly, the development of creative industrial districts should attach importance to the innovative development of the urban fringe areas, and embody the development characteristics of the creative industry in the space innovative application and economic interactive growth mode. In the process, it is necessary to consider about the reconstruction and utilization of the original ancient urban area, reduce the development cost of the creative industrial districts and better realize the economic benefits in the future development process. At the same time, the development of creative industrial districts should attach importance to the mastery of new economic growth points and utilize the relevant preferential policies to better realize the development objectives.

\section{REFERENCES}

[1] Liao Shuanghong, Xiao Yanfei. A Study of the Dynamic Mechanism and Models of Revolution of Creative Industrial Cluster [J]. East China Economic Management, 2011, 12: 49-52. 
[2] Ding Xinjun, Tian Fei. Cultural Tourism Creative Industrial Parks: Economic Space Dynamic Mechanism and Practice Innovation - A

Case of Cultivation of Tangshan Cultural Tourism Creative Industrial Park [J]. Special Zone Economy, 2011, 12: 163-165.

[3] Yi Hua, Yi Xiaoyun, Liu Chang'e. Research Review of Development Dynamic Mechanism of the World's Urban Creative Industrial Parks [J]. Inquiry Into Economic Issues, 2012, 02: 127-130.

[4] Xiao Yanfei, Liao Shuanghong. Study on Innovative Model of Urban Space Based on the Development of Creative Industry Districts [J]. East China Economic Management, 2012, 08: 28-31. 